\title{
Nuevos Conceptos en la Aterosclerosis Carotídea
}

\author{
Editor: F. Rubio
}

\author{
Simposiocelebrado el 20 de mayo de 1999 durante el XI Congreso Nacional de la SociedadEspañola de Neurología, \\ Santiago de Compostela, 19 al 22 de mayo de 1999, bajo los auspicios del \\ Grupo de Estudio de Enfermedades Cerebrovasculares de la Sociedad Españolade Neurología.
}

\section{Introducción}

\section{F. Rubio}

Las principales lesiones ateromatosas que comportan estenosis significativas y que son valoradas por el neurólogo son aquellas que afectan a la arteria carótida. En especial, nuestros enfermos están sujetos a problemas que se sitúan de forma preferente en labifurcación carotídea. Estalocalización se presenta como muy accesible no sólo a la angiografía digital, sino también a las técnicas de neuroimagen que actúan de forma incruenta y que, por tanto, son mucho más factibles a la repetición y valoración de forma secuencial en la evolución del proceso: angio-RMy ultrasonografía. Con estas técnicas se consigue una valoración precoz del cuadro, en fases asintomáticas, y se puede asistir a la evolución del mismo de forma espontánea o en respuesta a diversos tratamientos. En este aspecto terapéutico, los antiagregantes plaquetarios como la aspirina o el clopidogrel han demostrado su efectividad en la prevención de infartos cerebrales y deben combinarse con el tratamiento de los factores de riesgo. La bifurcación carotídea se manifiesta de forma muy accesible a la endarterectomía y ha demostrado su eficacia en estenosis de más del $70 \%$, en personas con isquemia transitoria o déficit residual discreto; la angioplastia se abre camino en espera de datos convincentes. Sin embargo, muchas incógnitas sobre la patogenia de la placa de ateroma, aspectos genéticos, nuevas capacidades de diagnóstico o de tratamiento, están a punto de ofrecer nuevas esperanzas a las personas que padecen aterosclerosis de los vasoscarotídeos.

La terapia génica-aún en fase experimental-representa un método nuevo en el tratamiento de la enfermedad vascular basado en la transferencia de ADN complementario a los vasos arteriales, cuya misión es controlar el crecimiento (placas de ateroma), modificar su función (espasmo posthemorragia subaracnoidea) ofacilitar el crecimiento de vasos colaterales (oclusiones intracraneales). Pero además, existiría la posibilidad de reducir el tamaño de la lesión cerebral por la inhibición de las citoquinas.

Algunas infecciones crónicas relativamente frecuentes entre la población general pueden ser causantes o coadyuvantes del desarrollo de las placas de ateroma. Se conocen datos sobre citomegalovirus, herpes o Helicobacter, pero sobre todola Chlamidia Pneumoniae aparece en los estudios fisiopatológicos o serológicos. No obstante, persiste la duda sobre el significado real del germen enlaplaca: $¿$ eselinductor dela placa osimplemente anida en ella?

La ultrasonografía mediante velocimetría Doppler, oimagen ecográfica, posee una alta fiabilidad y es -como ya hemos citadouna técnica reproducible por su accesibilidad y bajo coste. El conocimiento de lesiones extracraneales eintracraneales, la delimitación de los caracteres de las placas, las posibles imágenes de ulceración, la fragilidad de la placa o la detección de émbolos de la misma, representan avances importantes de cara al manejo de laateromatosiscarotídea.

Diversos hipolipemiantes del grupo de los inhibidores de la HMG CoA reductasa se están demostrando eficaces o están en vías de ensayo en la actualidad. Los primeros datos son alentadores en cuanto a la prevención de infartos cerebrales y sonútiles no sólo en individuos con hipercolesterolemia, sino también en personas con valores de laboratorio normales.

La formación y desarrollo de la placa de ateroma es un proceso multifactorial: lípidos plasmáticos, LDL a nivel de la placa, Lp(a), alteración del endotelio, trastornos de flujo, daño mecánico, alteraciones de las células mastocitarias productoras de histamina o prostaglandina $\mathrm{D}_{2}$, etc. El tamaño del núcleo ateromatoso constituye un factor de riesgo de mala evolución de las placas de ateroma.

En los trabajos que presentamos a continuación han participado destacados especialistas que investigan la enfermedad cerebrovascular desde la vertiente clínica, los laboratorios de neurologíaolasáreas experimentales, yencontraremosabundantesdatos de interés para la práctica diaria así como un estímulo para la realización de nuevos estudios con los que mejorar el porvenir de nuestros enfermos.
Recibido: 20.05.99. Aceptado: 25.05.99.

Servicio de Neurología. Ciutat Sanitària i Univ. de Bellvitge. L'Hospitalet de Llobregat, Barcelona, España.
Correspondencia: Dr. Francisco Rubio Borrego. Servicio de Neurología. Ciutat Sanitària i Univ. de Bellvitge. Feixa Llarga, s/n. E-08907L'Hospitalet de Llobregat, Barcelona.

(C) 1999, REVISTA DENEUROLOGÍA 